\title{
Highlighting the Salient Safety Issues in the National Road Traffic Regulation 2012
}

\author{
Iyowuna Festus Tubobereni*, Opiriba Karibi Ikiriko
}

Department of Urban and Regional Planning, School of Environmental Science, Port Harcourt Polytechnic, Port Harcourt, Nigeria

\author{
Email address: \\ iyofeshu@yahoo.com (I. F. Tubobereni) \\ ${ }^{*}$ Corresponding author
}

\section{To cite this article:}

Iyowuna Festus Tubobereni, Opiriba Karibi Ikiriko. Highlighting the Salient Safety Issues in the National Road Traffic Regulation 2012. Landscape Architecture and Regional Planning. Vol. 4, No. 2, 2019, pp. 21-27. doi: 10.11648/j.larp.20190402.11

Received: September 27, 2019; Accepted: October 11, 2019; Published: October 21, 2019

\begin{abstract}
Land transportation is an integral part of modern day life. It has bridged spatial activities, enhanced commerce and general developments across large areas of society. However, it has also resulted in series of untoward consequences that have negatively affected families as a result of different fatalities. It is obvious that the regulating authorities do not implement the provisions of the law especially as it relates to the periodic certification and recertification of commercial transport drivers and their conductors. It is also obvious that the will to confront security personnel/corporate security vehicles using by the enforcement agencies that grossly violate the provisions of the law is lacking. The law is silent on safety issues such as tire life and conditions, road markings or dressing and geometric design features of the roadways that influence driving. Therefore, the need to institute measures to regulate/control operations, use and behavior on public roads by pedestrians, drivers and other vehicle users became apparent in Nigeria. The 2012 National Road Traffic Regulation was therefore prepared to guide all public road users in relation to their conduct and use of road infrastructure. The complete disregard by the public and enforcement agencies of the regulation has, therefore, necessitated highlighting of some salient safety issues in the regulation which will lead to a better use of our roads and highways when adhered to. These ranges from the registration of vehicles to the processes of the issuance of drivers licenses, parking speed and other personal conducts that could jeopardize the safety of persons and property of potential road users.
\end{abstract}

Keywords: Roads, Traffic Regulation, Safety, Drivers, Road Users, Safety Issues, Land Transportation, Modern Day Life

\section{Introduction}

Land transportation is as old as man [1] - from man being his own means of propulsion (foot) to series of inventions in transport development that has amongst others culminated in the automobile. Beginning from the mid twentieth century, the increased use of the automobile has reshaped, not only the structure of our settlements and the location of activities but also the relationships between settlements, production, commerce, leisure and others. Attendant to the increase in the use of automobiles are the spatial spread of activities, construction of roads, motorways and highways for expeditious movement between locations. The resultant effect is the desire to increase speed to close the gap. In all transportation in general and motor vehicle, transportation has contributed immensely to the wellbeing and growth of the economy [2].
The need to harness such positive input to national development elicited the development of transport policies in most countries, including Nigeria. However, the positive input to the national and local economy, the facilitation of neighbouring and leisure and other positive outlooks are not without problems. The demand for fast cars have pushed manufacturers over the years to improve technology to design and improve the speed of cars that have been applauded in some quarters while the development has caused misery to families, communities and society due to fatalities resulting from several factors including speeding on the roads and highway. The widespread use of cars and increased use of speed have concomitant increase in fatalities, loss of property and other negative and debilitating impacts arising from the usage of motor vehicles of different types, size and, speed; by people of different age, education, agility and socio-economic status. These have, over the years, 
necessitated the regulation of the system. Road traffic legislations and codes are therefore the direct result of the need to maintain the safety of all road users and property in the society.

Amongst such measures in the past two decades in Nigeria does the passage of Road Traffic Act, Road Traffic Regulation and setting up of additional statutory agencies to enforce the provisions of the laws in collaboration with others already exist. The effects of unsafe acts and importance of safety on public roads and highways cannot be over stated over the years; this paper therefore ties to identify the salient safety features of the Road Traffic Regulation in Nigeria and its operationalization in Rivers State.

\subsection{Objectives of the Road Traffic Regulation Act 2012}

The concern to achieve safe movement within and between locations, economic development and wealth creation and national integration is not limited to a single country. Efforts internationally are therefore made to standardize and adopt international best practices. To this effect, the National Road Traffic Act was enacted with the objectives of:

i. Give effects to two international conventions on Road traffic and Road Signs and Signals.

ii. Provide operational requirements, rules and regulations for road traffic operations and operators.

iii. Make provisions relating to exempted bodies, operators of transport services, operation of ambulance services and towing vehicles; and

iv. Provide miscellaneous motor traffic regulations to ensure road safety through personal conduct, interpersonal relationship and handling of vehicles/traffic on public roads.

\subsection{Registration of Vehicles}

Salient safety issues in the National Road Traffic Regulation on registration of vehicles and other related matters are discussed from Part II-VI, of the Regulation (pp, B1530-46). It focused centrally on the methods of application for the registration of vehicle and issuance of licenses. It noted that the registration of all manner of motorized traffic/vehicles (vehicles and motorcycles) is to ensure that the vehicle can easily be identified and owner traced or reached in emergencies or when necessary through the issuance of vehicle license and motor Plate number.

The provisions in this section not only provide the categories of vehicles and their features; the basis for the use of the vehicle in the country, but also re-registration in cases of change in status of the vehicle. Furthermore, this section specifies change in ownership and colour of vehicle for the purposes of security. To ensure that a driver with a vehicle on the road is fit to be in charge or control of a vehicle, the law made regulations for the training of potential drivers. It sets guidelines for the establishment of driving and licensing of driving schools including the certification of driving instructors in the Federation [3]. Fines are stipulated for offences under this section.

\subsection{Learners Permit, Issuance and Revocation of License}

The focus from part VII-IX (pp. 1546-1562), the regulations to ensure that a potential driver is properly groomed to drive on the roadways in the country after a period of learning in a driving school, the regulation specified the issuance of learners' permit that will be usable for three months. It spelt out the conditions wherein the learner, issued with such permit will drive on the road and accompanied only by licensed instructor and not a passenger.

Often times, this section is violated in the state as vehicles with such learner's signs are seen with only the driver on the driver's seat, it is equally often unknown to the public the competence of the person driving at the stated time [3]. In the same vain the regulation categorized driver's license and learners permit into classes A-J for purposes of ensuring that those within a licensed permit for a particular class do not go over to drive other categorizes so as not to jeopardize public safety. Also specified is the age limits of those entitled to apply for a driver's license and the conditions that such would have undergone for a new applicant, for example, tutelage in a driving school and a successful administration of driving test.

Furthermore, a medical fitness attestation and visual acuity must be submitted with an application and biometric capture. It also specified the requirements for the issuance of commercial driver's certification. Conditions for the swap of license categories involve the test to ascertain fitness to handle such category of vehicle before the new license would be issued. Provisions are also made to license diplomats in the usage of cars in the country. For purposes of security which translate to safety, driver's license is personalized with signature and fingerprint capture embedded in the license.

The terms and conditions for the revocation of driver's license are copiously specified which include falsification to obtain license, negligence, use of drugs and alcohol, defective vision, neurological, muscular and other forms of ailments. The competence test which is undertaken as driving test is a practical exercise focused on the following: Control of vehicle in the traffic, stopping of vehicle from normal speed; turn corners, crossing main roads and turn from side to main roads; passing or overtaking other vehicles on the roads; backward movement along a straight road and around corners; turn round in a road; understanding all the displays on the dashboard including all indicators and figures shown on the speedometer of the motor vehicle; demonstration of knowledge of the rules of the road, the signals set out, to these Regulations, signs and traffic light signals illustrated. First aid skill and the principal offences set out under the Act and Regulations.

Others are read at a distance of twenty-three meters in daylight (with the aid of glasses, if worn), a motor Vehicle Identification Number Plates; and generally drive competently a motor vehicle or in the case of a person suffering from disability, a motor vehicle of the particular class of which the application relates, without danger to and with due consideration for other road users. The law also 
noted the difference between driving an automatic transmission fitted vehicle during the test to so grant license with the non-automatic vehicle.

Due to the need for caution and safety of passengers, the law mandates all commercial driver's license holders to undergo a minimum of cumulative nine hours of competence training within a period of three years which qualifies them to be issued a certificate of competence which shall form part of the requirements for renewal of the license. So also is the special training and licensing of convoy drivers which are usually associated with high speed. For the sake of safety of the public, the law spelt out situations for convictions that would lead to the withdrawal of license from a driver which include: "driving under the influence of alcohol or any drug; participating in, or organizing an unauthorized speed contest on a public highway; receives 3 convictions for failure to maintain insurance; receives 3 convictions for inconsiderate driving within 3 months; receives 3 convictions for failure to properly secure or use child restraint system in a vehicle; exceeding the prescribed speed limit; driving with defective and uncorrected eyesight; or where a driver has accumulated more than 14 penalty points within 12 calendar months."

Furthermore, the law made an offence "for any person to authorize, order, consent or knowingly permit the operation of any motor vehicle owned by him or under his control by any person, when he has knowledge that such person is disqualified or has no legal right to do so."To effectively distinguish a driver permitted to drive a stage carriage or omnibus, the law prescribed the use of a badge which is obtainable only by valid driver's license owners while a conductor is equally required to apply for and obtain a conductor's badge. This is for the purposes of control, to prevent a conductor from usurping the function of a driver. It explicitly stated the conditions of revocation of both licenses.

\subsection{Taxis, Stage Carriages, Omnibuses and Motorcycles for Hire}

As a caveat in part X-XII (pp. 1562-1588), the law prescribed to be posted the capacity of each of the above system on the vehicle to prevent over loading as it did specify that the vehicles are appropriately marked for ease in identification with the colour code of the locality. Under this section, seat conditions and sizes are prescribed including driver's seat area.

Also, are clear conditions for the carriage of passengers, goods, passengers and goods, and the protection of fright or goods in transit. Besides, the conditions for the use and safety of motor cycle riders and its passengers are spelt out. Furthermore, the condition for hiring, refusal to be hired and conduct between the driver, conductor and the hirer are made known.

The requirement and methods of operation of school bus is also captured. Documentations of intercity passenger vehicles are prescribed which includes the preparation of passenger manifest. Other commercial vehicle size, capacity, and weight; its load carrying system, tools, safety materials and warning systems are properly articulated in the law. The number and conditions of the breaking system appropriate to a vehicle is specified; even as measures to avoid noise pollution and excessive gaseous emission are instituted.

Other safety systems whose working conditions are mandatorily specified are: functional headlights, parking lights and traffic ting lights, illuminators and two side lights, less illuminating lights for bigger vehicles to show the width of the vehicles, while also stating the limitations in the number of lights that should be used without causing nuisance [4]. Other requirements in a vehicle as stated in the law are:

Have reflective red and silver tapes fitted to the rear and sides of the vehicle.

a) Electric horn sounding not more than a single note.

b) Equipped with at least two mirrors which shall be fitted externally, one on the offside and the other on the nearside of the vehicle which shall assist the driver to be aware of traffic to the rear and on both sides rearward.

c) Fitted in the front and rear seats, seat belts and child safety seats which shall be securely worn by the driver and the other occupants of the vehicle while the vehicle is on motion.

d) The driver of a motor vehicle shall be responsible for the children who are passengers in such a vehicle and shall ensure:

i. The proper use of child locks in every vehicle where one is installed;

ii. The proper use of child safety seats for every child that is 7 years and below but not in the front seat.

\subsection{Other Vehicle Features}

All vehicles on the road must have effective and appropriately functional wheel, steel hub or axle tree. Vehicle or trailer with a defective wheel, steel hub, or axle tree, shall not be used on any public road. Also included in the law are: the provision of vehicles with a strong and unreliable steering gear, steering apparatus fitted on the right hand side of the vehicle.

The prescribed standard of windscreen is laminated or safety glass that would not shatter when it breaks on impact and also clear enough as not to obscure the vision of the drivers while the vehicle is being driven on any public road. For visual clarity during rain, it is mandated that all motor vehicles must be fitted with electronically or mechanically operated windscreen wipers which shall be maintained and kept in proper working condition.

Other requirements instituted for safety on the road are the provision of trailers with mudguards to catch as far as practicable mud or water thrown up by the rotation of the wheels, this is not only to protect the trailer but especially vehicles at the rear from being blinded with mud raised to its windscreen including possible damage to the windscreen. Every motor vehicle shall be fitted with an efficient speedometer which shall be plus or minus ten per cent accurate at 50 kilometers per hour and shall be maintained in proper working condition at all times so as to gauge speed. 
Safety requirements for Tankers carrying spirit, explosives or other inflammable substances are the installation of the tanker with double pole armored wiring with insulated return electrical units and a battery insulation master switch; carrying of warning danger labels to be displayed conspicuously at the front and rear of the vehicle as carrying of additional freight or load on top of the vehicle is prohibited. Vehicles which convey hazardous materials cannot be used to transport other materials.

Reflex reflectors visible to an approaching driver $150 \mathrm{~m}$ away in clear weather when illuminated by light of the rear vehicle are mandatory, while all vehicles are to be certified road worthy by a Vehicle Inspection Officer who is mandated to issue a certificate valid for six and twelve months for commercial and private cars respectively. Parking of heavy goods vehicle on the road is also prohibited.

\section{Rules on Speed and Road Crossing}

This section considers guidelines on speed limits, parking of vehicles on the road and, turning/crossing on the road atgrade rail line crossing.

\subsection{Speed Limits}

Part XIII from page 1588, prescribes speed limits for different categories of vehicles and roads in the country. The law specified that no driver should drive recklessly any vehicle or drive at a speed more than the prescribed limits for the category of vehicle and road; therefore, it is also an offence to drive a vehicle on the road not fitted with a speed limiter, stating the measure with which regulators can use in determining speed of vehicles.

The law, however, recognized and exempted certain categories of official vehicle drivers on duty from prescribed speed limits noting that such drivers must proceed to do so taking cognizance of the safety of other road users; fitted with a device capable of emitting a sound (siren) and with an identification lamp (flashers and beacon lights).

\subsection{Sirens and Traffic Signs}

The regulation also identified those that are permitted to the use of siren on the road (part XIV, pp. 1589). It states that all drivers driving a vehicle must obey established authority in control of vehicles either verbally or by sign to stop, slow down or any directed line of action. Instructions by the Act is to obey all traffic signs or traffic signals on any public road and all notices on any public road where such notices are erected or exhibited by an authority responsible for the construction or maintenance of the public road, for the purpose of prohibiting, restricting, or regulating traffic over bridges or sections of the public road; stop when approaching a pedestrian crossing to allow pedestrians standing at the pedestrian crossing to cross the road.

It further inputted that no person shall damage, remove or alter or reposition any road traffic sign or traffic signal, or any other sign, signal, marking including colour and lettering or other device, displayed without lawful authority. The importance of functional trafficator lights and methods of usage in addition to the use of hand to indicate direction are highlighted. It stated that turning vehicles must give adequate and sufficient notice on the road before such turning is negotiated.

\subsection{Rules on Road Crossing}

Part XVII (pp.1591) Rules on vehicular road crossing. The rules are centered on crossing of roads when there are no obstruction of vehicles due to clear traffic and sufficiency of distance from another vehicle to allow access to cross and non-endangering of other road users; the rules also established the process of entering an intersection or other marked area, noting that, unless there is sufficient space on the other side of the intersection or other marked area to accommodate a vehicle, the operating vehicle must ensure the vehicle does not impede or obstruct the passage of other vehicles or pedestrians, notwithstanding any traffic-control signal indication to proceed; except when overtaking vehicles proceeding in the same direction, pass such vehicle only on the left side.

A driver or operator of a vehicle must not enter a public road unless he can do so with safety to himself and other road users; a driver is required to reduce his speed considerably when approaching a school or playground; and at all times give preference to children, the elderly, the physically challenged and visually impaired persons with any sight aid who wish to cross the road at pedestrian crossing points.

\subsection{Overtaking}

Furthermore, rule XVII (b) which specified measures for overtaking, succinctly stated in the regulations that drivers must recognize and respect road lanes as marked noting the width of their vehicle; crossing into another lane must be done without obstructing or endangering other road users and the slowdown of vehicles where necessary to be overtaken and passed by an approaching vehicle. Vehicular speed characteristics, directions or sides and conditions for overtaking are considered and stated.

Conditions that are not permitted also include: stopping of vehicles within8 meters from any corner, distraction and not being in full control of a vehicle and not having proper visibility, not take due cognizance of all traffic signs and notices lawfully placed on or near a road for the guidance of drivers; the lane to be used by slow moving vehicles and the placement of disabled vehicle on the road.

\subsection{Parking of Vehicles}

Part XVIII spelt out the regulations on parking. It stated that all vehicles parked on the road must not cause orlikely to cause danger, obstruction or undue inconvenience to other road users but park in a manner where specified, according to the specification. It prohibited a driver of a vehicle from parking the vehicle at or near a road crossing, a bend, top of a hill or a humpbacked bridge; on a foot-path; near a traffic 
light or pedestrian crossing; on a main road or one carrying fast traffic; opposite another parked vehicle or as obstruction to other vehicle; alongside another parked vehicle; on roads or at places or roads where there is a continuous white line with or without a broken line; near a bus stop, school or hospital entrance or blocking a traffic sign or entrance to a premises or a fire hydrant; on the wrong side of the road; where parking is prohibited; or away from the edge of the footpath.

\subsection{At-grade Rail Crossing}

An attempt at crossing of a rail line during the approach of a train is prohibited especially when there is any form of sign (manually, mechanically or electronically) indicating such or even where the train is visible to the driver. It further stated that no attempt be made at driving any vehicle through, around or under any railway crossing gate or lowering of barrier at a railway crossing or while such gate or barrier is closed or is being opened or closed; prescribing a minimum of 5meters stop distance from the closest level rail crossing.

\section{Rules and General Duties of Drivers}

This section (XIX) specified the general conduct of drivers while driving on public roads and the appurtenances that should not be added to a vehicle.

\subsection{Phone Calls}

The law succinctly disapproved the making and receiving of calls while driving by a driver of a vehicle and even an instructor giving instruction to a learner on the road which it notes to include, sending or receiving oral or written messages. The exception to this rule is if the call is for genuine emergency to either the police, fire service, ambulance or any emergency services.

\subsection{Dangerous Driving}

The rules described dangerous and reckless driving which it prescribed heavy fines on, such as causing vehicle to drive backwards long distance instead of turning; following another vehicle more closely than is reasonable and prudent having regard to the speed of such other vehicle and the condition of the road; driving a vehicle between sunset and sunrise without the use of lighted lamps; permitting any person, animal or object to occupy any position in such vehicle which may prevent the driver from exercising complete control over the movements of the vehicle or signaling his intention of stopping, slowing down or changing direction; permit any person to take hold of or interfere with the steering or operating mechanism of the vehicle and the driver not occupying the proper position such that the driver losses control and does not have a full view of the road ahead.

Other actions with caution within this section are: running the engine of a vehicle unattended to or not taking precautions before starting the engine of a vehicle such as non-stationary vehicles; abandonment of broken down vehicle at the center of the road without moving it to the appropriate place with necessary precaution signs/signals; permitting any person to ride on the wings, running boards, fender, or sides of the vehicle except for the purpose of testing the vehicles during repairs; permitting, in the case of a commercial vehicle, any person to ride on the steps, tailboard, or roof of the vehicle, nor on any load or freight on the vehicle or on any trailer and permitting any person to be carried in the vehicle being pulled except the person in charge of controlling the vehicle.

\subsection{Other Prohibitions}

The regulation prohibits excessive emission of gas and fumes from the engine, and negligently or willfully depositing or causing to be deposited any petrol or other liquid fuel or any oil or grease or other flammable or offensive matter, ashes or other refuse, of whatever nature, from vehicles on or alongside a public road; allowing a vehicle engine run while petrol or other flammable fuel is being delivered into the fuel tank or starting of an engine before the conclusion of fueling and closure of tank cover; falling asleep while driving or in control of a vehicle; allowing any person to enter or alight from a vehicle on a public road, unless such vehicle is stationary and unless the person can do so with safety to himself and other road users; driving without a spare tire and other necessary tools and overloading of a vehicle.

\subsection{Condition of Drivers}

Part XX hinges on regulating drivers' fitness to drive on the road, the rule specified that no driver should be on the steering for more than ten and half hours within twenty-four hours. The driver is expected to have eight hours of continuous rest within a twenty-four hours' period and thirty minutes of rest every three hours in a trip that exceeds five hours. It noted that any time spent by a driver on other work in connection with the vehicle or load carried thereby shall be reckoned as time spent in driving.

\subsection{Pedestrians and Pedestrian Crossing}

Pedestrians are to observe and obey traffic signals at even pedestrian crossings though the driver of a vehicle is mandated to yield the right of way by slowing down or stopping (part XXIII). Pedestrians are not allowed to suddenly enter a pedestrian crossing and walk or run into the path of a vehicle which is so close that it will be impossible for the driver to yield as mandated. Vehicles are not permitted to overtake a stopped vehicle at a pedestrian crossing. Crossing at pedestrian crossing must be done with dispatch or swiftly; where pedestrian overhead bridge is provided, pedestrians must use the overhead bridge but if dependent on pedestrian crossing, all such crossing may be done within 91.44 meters.

Pedestrians must use sidewalks on the road or as near as 
the side of the road as possible where sidewalk is not provided. The law further stated that no pedestrian should cross a public road without satisfying himself that the road is sufficiently free from on-coming traffic to permit him to cross the road in safety and should not conduct himself in such a manner as to or as is likely to constitute a source of danger to himself or to other road users on such road.

\subsection{Driving and Alcohol/Drugs}

Part XXIV stated that no person should drive a vehicle or occupy the driver's seat of any vehicle on a public road while under the influence of intoxicating liquor or a drug having a narcotic effect while the engine is running. It stated the prescribed alcohol limits of 0.5 grams in 100 milliliters of alcohol or 80 milligrams in 100 milliliters of urine or blood test which shall be determined by use of a breath analyzer or in case of urine or blood test by a medical officer who shall make a report on the results of the test, stating measures for refusal to be subjected to such test.

\subsection{Removal of Vehicles}

The rule stated that there will be issuance of parking ticket to an inappropriately parked vehicle or vehicle parked in contravention of established parking system or standard which will precede the removal of the vehicle by an authorized authority, giving a twenty-hour notice (part XXV). The vehicle to be so removed would have been parked in a position or condition that would cause obstruction or constitute danger to other road users.

\subsection{Prohibitions on an Expressway}

Part XXVI of the regulations prescribed the different types of vehicles permitted to be used in an expressway. One maximum permissible size is larger trailers with extra-ordinary axle load and load that can be placed on it. Also prohibited on the expressway, are the movement, trading and grazing of cattle or livestock, tri-cycles, smaller motorcycles, hand pushed trucks, bicycles of all types, agricultural machines and pedestrian movement. While pedestrian movement will be permissible only in designated areas, the loading and offloading of passengers or goods will be restricted to only designated locations or bus stops.

It cautioned against the opening of the door of a vehicle by any person including the driver towards the moving traffic side unless reasonably safe and the alighting from a vehicle that is not stationary on the road. Furthermore, it cautioned against overloading of vehicles particularly of persons, and goods beyond the manufacturers specification. It also specified measures to be taken to bring the excess to the limits of the vehicle. It noted that the stopping or repair of vehicles on the carriageway of an expressway is prohibited. Improper entry and/or exit, crossing of the central reserve or making of U-turns except on designated areas are not permitted $[5,6]$.

\subsection{Conditions for the Use of Bicycles}

Bicycles for use on the road must be fitted with appropriate braking systems and an efficient bell or warning system, mudguard [6-8]. Riders of bicycle must not be attached to a moving vehicle, not wear an approved safety helmet or carry a passenger who is not wearing an approved helmet and ride in a negligent or dangerous manner especially under the influence of alcohol, drugs and other psychotropic substances to such extent as to be incapable of having proper control of the bicycle [9-11].

\subsection{Regulations for Operations of Transport Operators}

Part XXXIII of the regulations mandates all fleet transport operators who engage in inter-state city road transport services to establish a Safety Unit and appoint a Safety Officer as the head of the Unit who shall ensure that safety is maintained in the system and also be registered for licensing [12-14]. Emergency phone numbers must be inscribed on fleets as they are to maintain records of drivers, vehicles, routes plied and road crashes and their causes, and submit same on regular basis [14-16].

\section{Conclusion}

The different sections of the regulation succinctly made provisions for the conducts that will lead to the safety of the country's roads and highways. Substantial provisions in the regulations are however not obeyed and utterly ignored without proper enforcement by the public and the regulators. To a large extent the failure to obey the content of the regulation even by the relatively educated in the society is attributable to ignorance on the part of the public.

It would be important to start early to introduce some of the content of the regulations to students below the tertiary school age. The strict adherence to the training system espoused in the regulation and even furtherance to include written text would improve driver's knowledge of the provisions in the law. Also, it is obvious that the regulating/enforcement authorities do not implement the provisions of the law especially as it relates to the periodic certification and recertification of commercial transport drivers and their conductors. Besides, the will to confront security personnel and other corporate security vehicles (bullion vans) by the enforcement agencies that grossly violate the provisions of the law is lacking. The law is silent on some other safety issues such as tire life and conditions, road markings or dressing and geometric design features of the roadways that influence driving.

\section{References}

[1] Okoko, E. (2006). Urban Transportation Planning and Modelling. Akure: Millennium Publishers.

[2] Gazette, F. R. (2012). National Road Traffic Regulations. Lagos: Federal Government Printers. 
[3] Oyediran, P. A. (2008). Road Transport Policy and Traffic Management in Nigeria. Journal of Research in National Development Vol. 1.

[4] Zogby, J. J. (2000) Transportation Safety Management Systems. A3B01: Committee on Transportation Safety Management Central Missouri State University.

[5] Tubobereni, I. F. and Ikiriko, O. K. (2019). Urban Bias in Resource Allocation: Implications for City Development. Academia Arena, 11 (8): 59-70.

[6] Tubobereni, I. F. and Ikiriko, O. K. (2019). Impact of Urban Renewal Projects on the Socio-Economic Groups in Port Harcourt. World Rural Observation, 11 (3): 15-24.

[7] Chiuba, O. D. (2002). Environmental and Urban Renewal Strategies: Theoretical and Analytical Frame Works University of Nigeria, Enugu Campus, Institute for Development Studies.

[8] Dirokweni, J. O. (1999). The Problems of Slum Clearance Projects and the Rehousing of Displaced Persons in Port Harcourt' Thesis submitted to the National Council of the Nigeria Institution of Estate Surveyors and Valuers for admission into Corporate Membership.

[9] Duruzoechi, N. F. (2009). Housing Development and Public Policy (2ndedn). Owerri, Nigeria: Alphabet Nigeria Publishers.
[10] Ezenagu, V. C. (2000). Fundamentals of Housing. Awka, Nigeria: Fountain Publishers.

[11] Federal Republic of Nigeria (FRN) (1992). "The Nigerian Urban and Regional Planning Law (NURPL), Decree No. 88 of 1992.

[12] Imbasi, K. 1. (1994). Unpublished B. Tech (Urban and Regional Planning) Final Project Report. Rivers State University of Science and Technology, Port Harcourt.

[13] Jacobs, M. (1991). The Green Economy London: Photo Press.

[14] Kalu, R. E. and Ezirim, O. N. (2001). Urban Renewal (Perception and Planning) Enugu, Nigeria: Kenny and Brothers Enterprise (Nig).

[15] Mitlin, D. and Satterthwante, D. (1995). Sustainable Development and Cities," in Pugh, A. (ed) Sustainable Environment and Urbanization. London Earthscan Publications Ltd.

[16] Obafemi, A. A. and Odubo, T. O. (2013). Waterfront Redevelopment in Port Harcourt Metropolis: Issues and Socio-economic Implications for Urban Environmental Management." In The International Journal of Engineering and Sciences (IJES), 2: 12. 